\section{Bioactive isochromenone isolated from Aspergillus fumigatus, endophytic fungus from Bacopa monnieri}

\author{
Jay Prakash Thakur, Rumana Haider, \\ Dhananjay Kumar Singh, Balagani \\ Sathish Kumar, Prema G. Vasudev, Suaib \\ Luqman, Alok Kalra, Dharmendra Saikia, \\ Arvind S. Negi
}

CSIR-Central Institute of Medicinal and Aromatic Plants, Lucknow, India

\section{Abstract}

Fungal endophytes are a significant reservoir of novel bioactive secondary metabolites. Present communication describes isolation and structure determination of isochromenone, from endophytic microorganism Aspergillus fumigatus hosted in Bacopa monnieri plant. Further, its biological evaluation revealed it as antioxidant and antitubercular. The methanol extract of $A$. fumigatus inhibits the growth of the virulent strain of Mycobacterium tuberculosis $\mathrm{H}_{37} \mathrm{RV}$ with minimum inhibitory concentration $500 \mu \mathrm{g} / \mathrm{mL}$. This is the first report of isolation of isochromenone from $A$. fumigatus.

\section{Introduction}

Endophytes are microorganisms residing in the inter- and intra-cellular living tissues of host plant. These are harbored by the plants. Endophytes are mainly fungi, symbiotically benefit the host plant and adapt the microenvironment. These are considered as a good source of novel bioactive secondary metabolites for the development of pharmaceuticals and agrochemicals. ${ }^{1} \mathrm{~A}$ single endophytic strain can produce multiple bioactives. Diverse natural products are produced by endophytes like antibiotics, anticancer, antioxidants, immunosuppressants and other biologically active substances and many of them have been isolated. ${ }^{2,3}$ Brahmi (Bacopa monnieri) is an important medicinal herb used in Ayurveda system of medicine in India. The herb was described in Charaka Samhita, Susrutu Samhita and Athar-Ved to sharpen intellect and attenuate mental deficits. It is a perennial, creeping herb native to the wetlands of India. Other than India, it is also found in Europe, Asia, Australia, Africa and Americas. It grows well in marshy areas. Traditionally, this herb is mainly prescribed for neurological disorders like epilepsy. Its extract has shown potential cognitive effects. ${ }^{4}$ Bacosides are the main bioactive compounds of Brahmi. Present communication describes isolation and identification of an endophytic fungus from $B$. monnieri plant. Isolation of a fungal metabolite i.e. 6hydroxymellein is the first report from this fungus. ${ }^{1}$

\section{Materials and Methods}

\section{General}

General laboratory chemicals were procured from Thomas Baker, India. Deuterated solvents were procured from Sigma Aldrich USA. Thin layer chromatography was done on Merck aluminium sheet thin layer chromatography (TLC, $\mathrm{UV}_{254 \mathrm{~nm}}$ ) plates. NMR spectra were measured on a Bruker Avance $300 \mathrm{MHz}$ instrument. Tetramethylsilane (TMS) was used as an internal standard. Electron Impact ionization mass (EI-MS) were recorded on Perkin-Elmer Turbo Mass GC-MS system and ESI-High resolution mass was of compound 1 was done on Agilent 6520 Q-TOF. Biochemicals for bioevaluations were obtained from Sigma-Aldrich, India and Himedia Laboratories, India.

\section{Isolation of endophytic fungus from Bacopa monnieri}

The isolation was performed as per previously reported method. ${ }^{5}$ The healthy $B$. monnieri plant (Brahmi) (Herbarium no. CIMAP12597) leaves were obtained from Research Farm of CSIR-CIMAP, Lucknow, India. The leaves were properly washed in running tap water, double distilled water and cut into small discs (approximately $0.5 \mathrm{~cm}^{2}$ ). Leaf segments were surface sterilized with ethanol (70\%) for 5 seconds to eliminate epiphytic microbes. Samples were treated with $4 \%$ sodium hypochlorite $(\mathrm{NaOCl})$ for 3-5 minutes, rinsed in sterile saline water for 1 minute (4 times) and inoculated (1 mL) in NB (Nutrient Broth) or TSB (Tryptic Soy Broth) and incubated overnight at $28^{\circ} \mathrm{C}$ in shaker for sterility check. Samples (5.0 gm) were ground in sterile mortar pestle in sterile saline water $(5 \mathrm{~mL})$. Dilutions were prepared to $10^{-6}$. $100 \mu \mathrm{L}$ of aliquot was spread plated on PDA (Potato Dextrose Agar), plates were sealed with parafilm and incubated at $28 \pm 1^{\circ} \mathrm{C}$ till growth in a BOD incubator. The hyphae growth was observed from the tissues on PDA plates, immediately these were transferred into fresh PDA plates

\section{Molecular identification of the endophytic fungal strains}

Fungal genomic DNA was isolated from fully grown 4 days old culture as per standard proce-
Correspondence: Arvind S. Negi, Chemical Sciences Division, Central Institute of Medicinal and Aromatic Plants (CSIR-CIMAP), Kukrail Picnic Spot Road, Lucknow-226015, U.P., India. E-mail: arvindcimap@rediffmail.com.

Key words: Bacopa monnieri; Aspergillus fumigatus; endophyte; isochromenone; antioxidant.

Acknowledgements: The authors are thankful to Director CSIR-CIMAP for constant encouragement and support. Research fellowship received by one of the authors (JPT) from CSIR is duly acknowledged. This work was supported by Council of Scientific and Industrial Research (CSIR), India.

Contributions: the authors contributed equally.

Conflict of interest: the authors declare no conflict of interest.

Received for publication: 7 January 2015.

Revision received: 19 October 2015.

Accepted for publication: 19 October 2015

This work is licensed under a Creative Commons Attribution NonCommercial 3.0 License (CC BYNC 3.0).

CC Copyright J.P. Thakuret al., 2015

Licensee PAGEPress, Italy

Microbiology Research 2015; 6:5800

doi:10.4081/mr.2015.5800

dures. ${ }^{6}$ The quality and quantity of isolated DNA was checked spectrophotometrically (Nanodrop ND 1000) and through agarose gel electrophoresis as well. The universal primers ITSI (5,-TCCGTAGGTGAACCTGCGG-3,) and ITS 4 (5, -TCCTCCGCTTATTGATATGC-3, ) were used for amplification of the ITS gene from fungal strain. The fungal genomic DNA (25ng) and each primer ( 5 pmol) was used for amplification in a Thermocycler programmed as $95^{\circ} \mathrm{C}$ for $5 \mathrm{~min}$; 32 cycles of $95^{\circ} \mathrm{C}$ for $30 \mathrm{sec}$, $55^{\circ} \mathrm{C}$ for $30 \mathrm{sec}, 72^{\circ} \mathrm{C}$ for $1 \mathrm{~min}, 72^{\circ} \mathrm{C}$ for 10 min; $4^{\circ} \mathrm{C}$ for infinite period. The PCR product was purified with a PCR Cleanup Kit (Axygen, Union City, CA, USA) and directly sequenced using the forward universal primer and Big Dye Terminator v3.1 cycle sequencing kit (Applied Biosystems, Foster City, CA, USA) on a $3130 \times 1$ Genetic Analyzer (Applied Biosystems) as per manufacturer's protocol. Sequence analysis was carried out using the nucleotide BLAST (BLASTN) (NCBI).

\section{Fungal culturing}

The isolates were inoculated in an Erlenmeyer flask $(500 \mathrm{~mL})$ containing liquid medium $(100 \mathrm{~mL})$ and the cultures were incubated with constant shaking of $200 \mathrm{rpm}$ at $28 \pm 1^{\circ} \mathrm{C}$ for $96-120 \mathrm{~h}$. 


\section{Extract preparation and isolation of pure metabolite}

The isolates were harvested by filtration and the filtrates were centrifuged at $6000 \mathrm{rpm}$ for $15 \mathrm{~min}$, the supernatant as well as pellet were used for extract preparation. $40 \mathrm{~mL}$ of supernatant was mixed with $4.0 \mathrm{~g}$ of diaion HP20 (Supelco, Bellefonte, PA, USA) and shacked on a shaker cabinet at $28 \pm 1^{\circ} \mathrm{C}$ for $30 \mathrm{~min}$. The contents were packed in a plastic column. The resin was drained by applying gentle pressure using syringe plunger, washed with distilled water $(15 \mathrm{~mL})$, followed by elution with methanol $(20 \mathrm{~mL})$, and concentrated in vacuo at $40 \pm 1^{\circ} \mathrm{C}$ to get a residue. The residue (5.34 g) thus obtained was charged on a column (glass, $4 \times 80 \mathrm{~cm})$ using silica gel $(60-120$ mesh) and eluted successively with hexane $(1.2 \mathrm{~L})$, then increasing polarity of ethyl acetate $2 \%, 5 \%, 10 \%$, and so on each with $1.6 \mathrm{~L}$. The pure fractions 119-125 were mixed together and after evaporation yielded a pure gummy compound ( $27 \mathrm{mg}$ ) at $30 \%$ ethyl acetate-hexane. Its structure was established by spectroscopy (IR, ${ }^{1} \mathrm{H}$ NMR, ${ }^{13} \mathrm{C}$ NMR, DEPT etc. and mass) (Table 1 and Supplementary Material) and finally authenticated by X-ray crystallography.

\section{X-ray crystallography \\ of isochromenone 1}

Isochromenone $1\left(\mathrm{C}_{10} \mathrm{H}_{10} \mathrm{O}_{4}, M=194.2\right)$ single crystals were obtained by slow evaporation from ethyl acetate. The compound crystallized in monoclinic space group $P 2_{1}$ with two independent molecules in the asymmetric unit. The unit cell dimensions were as, $a=6.4616$ (5) $\AA, b=16.4391$ (12) $\AA, c=8.3548$ (6) $\AA, Z=4$, $\mathrm{V}=887.34(11) \AA^{3}, \mathrm{D}_{\text {calc }}=1.454 \mathrm{gm} / \mathrm{cm}^{3}, \mathrm{~F}(000)=$ 408. X-ray diffraction experiment was performed on a Bruker AXS SMART APEX CCD diffractometer using MoK radiation $(\lambda=0.71073$ $\AA)$, using combinations of $\phi$ and $\omega$ scans at room temperature $\left(20^{\circ} \mathrm{C}\right)$. The structure was solved by direct methods using SHELXS and was refined against $\mathrm{F}^{2}$ with full-matrix least squares method by using SHELXL. ${ }^{7,8}$ Nonhydrogen atoms were refined anisotropically. Hydrogen atoms attached to the hydroxyl groups were located from the difference Fourier maps were refined isotropically. Rest of the hydrogen atoms were geometrically fixed and were refined as riding over the atoms to which they are bonded. 7249 reflections were measured (3930 independent reflections) with $R_{i n t}=0.04$. Friedel pairs were merged prior to structure refinement. The final R-value was $0.0388(w R=0.0865)$ for 1748 observed reflections with [ $\mathrm{I}>2$ sigI] and for 269 parameters. The goodness-of-fit was 1.069. The largest difference peak was $0.21 \mathrm{e}^{-3}$ and the largest difference hole was $-0.27 \mathrm{e}^{-3}$. Absolute configuration of the molecule was not determined in the present study. Crystallographic data (excluding structure factors) has been deposited to the Cambridge Crystallographic Data Centre as supplementary publication number CCDC-998759. Copies of the data can be obtained, free of charge, on application to CCDC, 12-Union Road, Cambridge-CB2 1EZ, UK.

\section{In vitro antimycobacterial assay by BACTEC radiometric susceptibility assay}

The BACTEC TB medium (12B) is an enriched Middlebrook $7 \mathrm{H} 9$ broth base. Mycobacteria utilize a ${ }^{14} \mathrm{C}$-labeled substrate (palmitic acid) present in the medium and release ${ }^{14} \mathrm{CO}_{2}$ into the atmosphere above the medium. A test protocol adopted was as per Siddiqi. ${ }^{9}$ Isoniazid and rifampicin were used as standard drugs.

\section{Antioxidant activity \\ Total phenolic estimation}

The total phenolic (TP) content was determined by Folin Ciocalteau reagent (Phenol reagent) according to the reported method. ${ }^{10,11}$ Presence of total phenolic content was expressed as gallic acid equivalent obtained from standard curve of gallic acid.

\section{Estimation of total flavonoid content}

The total flavonoid (TF) content was determined using the spectrophotometrically with minor modifications. ${ }^{12}$ The results were expressed in terms of quercetin equivalent using a standard curve of quercetin with different dilutions.

\section{Reducing power assay}

The iron reducing power (RP) was established according to the previous method of with some modifications. ${ }^{13,14}$ The absorbance was taken at $700 \mathrm{~nm}$ against a reagent blank.

\section{Ferric reducing antioxidant power assay}

The Ferric Reducing Antioxidant Power Assay (FRAP) assay measures the antioxidant capacity to reduce the $\mathrm{Fe}^{3}+$ /tripyridyl-s-triazine (TPTZ) complex, to the ferrous form. The activity was calculated by comparing the concentration of each compound with the concentration of ferrous sulphate required to give the same absorbance change and results were expressed as FSE value. ${ }^{15}$

\section{$D P P H$ radical scavenging activity}

DPPH radical scavenging activity of different concentration of compounds from Aspergillus fumigatus was estimated according to method reported earlier. ${ }^{16}$ Results were expressed as percent inhibition calculated from reagent control.

\section{Total antioxidant capacity estimation}

The total antioxidant capacity (TAC) of different concentration of Aspergillus fumigatus was estimated as per previous method with minor amendment. ${ }^{17,18}$ Values expressed as ascorbic acid equivalent from standard curve.

\section{Nitric oxide scavenging activity}

Nitric oxide (NO) generated from sodium nitroprusside liberates nitric acid at physiological $\mathrm{pH}$. The nitric acid is converted into nitrous acid which on reaction with sulphanilic acid and naphthylethylenediamine (Griess reagent) forming diazo complex. The pink color of the product of the diazo coupling was measured at $546 \mathrm{~nm} .{ }^{19}$ The nitric oxide radicals scavenging activity was calculated using the equation;

$$
\left.\% \text { Inhibition }=\left(A_{0}-A_{1}\right) / A_{0} \times 100\right)
$$

where $A_{0}$ was the absorbance of the control (without test compound) and $A_{1}$ was the absorbance in the presence of the test compound.

\section{Results and Discussion}

A fungal endophyte was identified as $A$. fumigatus isolated from the leaves of $B$. monnieri plant. ${ }^{20,21}$ Methanol extract of $A$. fumigatus was subjected to repeated column chromatography on silica gel to get compound-1 as a light brown solid with mp $205-7^{\circ} \mathrm{C}$ (214$217^{\circ} \mathrm{C}$ ) which was identified as isochromenone derivative i.e. 6-hydroxymellein (1) by spectroscopy. The yield of this metabolite was about $0.51 \%$ in the methanol extract. ${ }^{13} \mathrm{C}$ NMR showed ten distinct carbons in the molecule. DEPT 135 experiment ascertained one methyl ( $\delta 20.32 \mathrm{ppm})$, one methylene ( $\delta 34.57)$, three methines $(\delta 75.85, \delta 101.46$ and 106.97) and five quaternary carbons $(\delta 101.17,142.68, \delta 164.79,164.79$ and one lactone at $\delta 170.22$ ). It was further confirmed by ESI-High Resolution Mass (ESI-HRMS) for $[\mathrm{M}+\mathrm{H}]^{+}$observed at 195.0668 against calculated value 195.0657. Based on ${ }^{13} \mathrm{C}$ NMR and HRMS mass its chemical formula was determined as $\mathrm{C}_{10} \mathrm{H}_{10} \mathrm{O}_{4}$. Presence of six unsaturated carbons at $\delta 101.17$ to 164.79 indicated presence of an aromatic ring. Its double bond equivalence (DBE) was six which clearly indicated presence of a bicyclic system. Acetylated product (2) showed ESI mass at $278\left[\mathrm{M}^{+}\right]$as diacetate derivative, indicating presence of two hydroxyls in the parent compound (1). Two exchangeable protons at $\delta 9.60$ and $\delta 11.29$ ascertained possibility of two phenolic hydroxyls $\left(\right.$ In ${ }^{13} \mathrm{C}$, oxygenated quaternary at 8164.79x2). From HSQC experiment chemical shifts of $3-\mathrm{CH}$ ( $\delta 4.68 \mathrm{~m}, 75.85), 4-\mathrm{CH}_{2}$ ( $\delta 2.90$ 
bs, 34.57), 5-CH and 7-CH together ( $\delta 6.28 \mathrm{~d}$, $106.97)$ and $11-\mathrm{CH}_{3}(\delta 1.53 \mathrm{~d}, 20.32)$ were established. In ${ }^{1} \mathrm{H}-{ }^{-1} \mathrm{H}$ COSY spectrum, 2-CH ( $\delta 4.68 \mathrm{~m})$ showed coupling with $3-\mathrm{CH}_{2}(\delta 2.90$ bs) and also with $11-\mathrm{CH}_{3}$ ( $\left.\delta 1.53\right)$ indicating presence of a $-\mathrm{CH}_{2}-\mathrm{CH}-\mathrm{CH}_{3}$ system.

In $\mathrm{HMBC}$ correlations (Figure 1), $4-\mathrm{CH}_{2}$ protons ( $\delta 2.90 \mathrm{bs})$ showed long range correlations with C3 (875.85), C5 (8106.97), C9 (101.17), $\mathrm{C} 10$ ( $\delta 142.68)$ and $\mathrm{C10}(\delta 20.32)$ while $5-\mathrm{CH}$ and $7-\mathrm{CH}$ protons $(\delta 6.28 \mathrm{~d})$ showed long range correlations with C4 (834.57), C6 (8164.79), C8 (164.79), C9 (101.17) and C10 (\$142.68). It was established as 3,4,-dihydro-6,8-dihydroxy3-methylisochromen-1-one (1). The ${ }^{1} \mathrm{H}$ NMR and ${ }^{13} \mathrm{C}$ NMR data were well in agreement with previously reported data. ${ }^{22}$ The structure was finally authenticated by X-ray crystallography (Figure 2). Previously, 6-hydroxymellein was isolated from Aspergillus terreus, A. fischeri, and $A$. ochraceus etc. ${ }^{23-25}$ To the best of our knowledge occurrence of 6-hydroxymellein in A. fumigatus is the first report from this fungus.

Its diacetyl derivative (2) was synthesized on treating compound with acetic anhydride in dry chloroform and 4,4-diaminopyridine (DMAP) at room temperature in $92 \%$ yield. It was confirmed by ${ }^{1} \mathrm{H}$ NMR (2xOAc at 61.84ppm) and EI mass at $278\left[\mathrm{M}^{+}\right]$(Table 1). Figure 2 provides a view of the asymmetric unit of compound 1 dimeric crystal. Both the molecules in the asymmetric unit have very similar conformations. There is an intramolec- ular $0-\mathrm{H}$.... hydrogen bond between the $\mathrm{C}=0$ group and one of the hydroxyl groups, resulting in 6-membered hydrogen bonded ring motif, in both the molecules. The two molecules are held together in the asymmetric unit by $0-\mathrm{H}$.... 0 and $\mathrm{C}-\mathrm{H}$.... $\mathrm{O}$ hydrogen bonds.

Methanolic extract of $A$. fumigatus was evaluated for ferric reducing capacity and free radical scavenging activity (Table 1) exhibiting maximum scavenging of DPPH radicals $(52.91 \pm 2.15 \%)$ at $100 \mu \mathrm{g} / \mathrm{mL}$ which was concentration-dependent. Contrary to DPPH scavenging activity, NO radical scavenging was almost half $(26.93 \pm 0.82 \%)$ at $100 \mu \mathrm{g} / \mathrm{mL}$ which further decreases at lower concentrations. Reductions of ferric to ferrous (Iron-free radicals) ions was also noticed and evidenced by increased absorbance at $700 \mathrm{nM}$ in extract

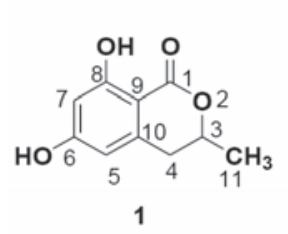

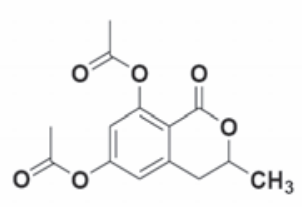

2: Diacetyl derivative

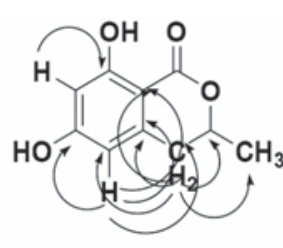

1

Figure 1. Structures of isochromenone (1), its diacetate derivative (2) and HMBC correlations of 1 .

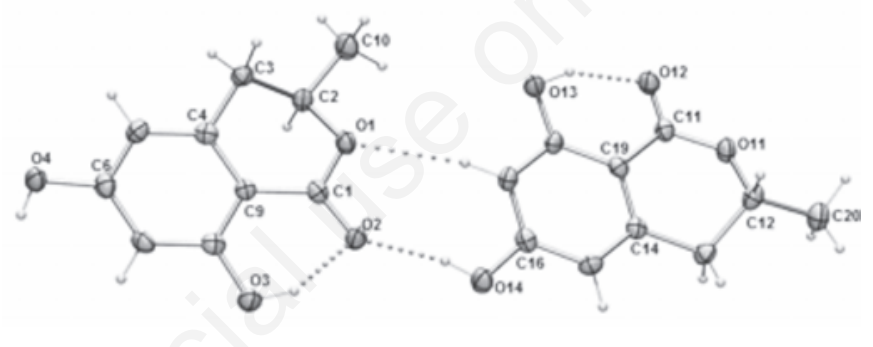

Figure 2. Asymmetric unit of the compound 1 crystals. Hydrogen bonds are indicated by dotted lines.

Table 1. Spectral data of isochromenone (1) and its diacetyl derivative (2).

\begin{tabular}{|c|c|c|c|c|c|c|}
\hline \multirow[t]{2}{*}{ Assignments } & \multicolumn{4}{|c|}{ Compound 1} & \multicolumn{2}{|c|}{ Compound 2} \\
\hline & $\begin{array}{c}{ }^{13} \mathrm{C}\left(\mathrm{CDCl}_{3}, 75 \mathrm{MHz}\right) \\
\delta \text { values }(\mathrm{ppm})\end{array}$ & $\begin{array}{c}{ }^{1} \mathrm{H}\left(\mathrm{CDCl}_{3}, 300 \mathrm{MHz}\right) \\
\delta \text { values }(\mathrm{ppm})\end{array}$ & $\begin{array}{l}\text { Mass (ESI mass)/ } \\
\text { ESI-HRMS }\end{array}$ & $\begin{array}{l}\mathrm{IR}\left(\mathrm{CCl}_{4},\right. \\
\left.\mathrm{Cm}^{-1}\right)\end{array}$ & $\begin{array}{c}{ }^{1} \mathrm{H}\left(\mathrm{CDCl}_{3}, 300 \mathrm{MHz}\right) \\
\delta \text { values }(\mathrm{ppm})\end{array}$ & $\begin{array}{l}\text { Mass } \\
\text { (EI mass) }\end{array}$ \\
\hline $\mathrm{Cl}$ & $170.22(\mathrm{QC})$ & - & ESI-MS: 195 & 3219 & - & $278[\mathrm{M}]^{+}$ \\
\hline $2(0)$ & - & - & {$[\mathrm{M}+\mathrm{H}]^{+}, 217$} & 2925 & - & \\
\hline $\mathrm{C} 3$ & $75.85(\mathrm{CH})$ & $4.64-4.73, \mathrm{~m}, 1 \mathrm{H}$ & {$[\mathrm{M}+\mathrm{Na}]^{+}, 233$} & 2854 & $4.20-4.27, \mathrm{~m}, 1 \mathrm{H}$ & \\
\hline $\mathrm{C} 4$ & 34.57 (CH2) & 2.89-2.94, bs, CH2 & {$[\mathrm{M}+\mathrm{K}]^{+}$} & 1735 & $2.36, \mathrm{~m}, \mathrm{CH} 2$ & \\
\hline $\mathrm{C} 5$ & $106.97(\mathrm{CH})$ & $\begin{array}{c}6.26-6.29, \mathrm{~d}, \mathrm{CH}, \\
\text { aromatic, J=7.2Hz \& } 1.5 \mathrm{~Hz} \text {. }\end{array}$ & $\begin{array}{c}\text { Negative } \\
\text { mode: } 192.9 \\
{[\mathrm{M}-\mathrm{H}]^{-}}\end{array}$ & $\begin{array}{l}1636 \\
1378\end{array}$ & 7.54, d, $1 \mathrm{H}$, aromatic & \\
\hline $\mathrm{C} 6$ & $164.7(\mathrm{QC})$ & - & ESI-HRMS; & & & \\
\hline $\mathrm{C} 7$ & $101.46(\mathrm{CH})$ & $\begin{array}{l}\text { 6.26-6.29, d, CH, } \\
\text { aromatic, J=7.2Hz } \\
\& 1.5 \mathrm{~Hz} .\end{array}$ & $\begin{array}{c}\text { Calculated for }[\mathrm{M}+\mathrm{H}]^{+} \\
\mathrm{C}_{10} \mathrm{H}_{11} \mathrm{O}_{4}= \\
\text { 195.0657, Observed, }\end{array}$ & & $7.69, \mathrm{~d}, 1 \mathrm{H}$, aromatic & \\
\hline $\mathrm{C} 8$ & $164.7(\mathrm{QC})$ & - & & & - & \\
\hline $\mathrm{C} 9$ & $101.17(\mathrm{QC})$ & - & 195.0668 & & - & \\
\hline $\mathrm{Cl0}$ & $143.68(\mathrm{QC})$ & $1.53, \mathrm{~d}, 3 \mathrm{H}, \mathrm{CH} 3, \mathrm{~J}=9.6 \mathrm{~Hz}^{-}$ & & & - & \\
\hline C11 & $20.32(\mathrm{CH} 3)$ & & & & $0.98, \mathrm{~d}, 3 \mathrm{H}, \mathrm{CH} 3$ & \\
\hline $\begin{array}{l}\text { 6-OH \& 8-OH (1)/ } \\
\text { 6-OAc \& 8-OAc (2) }\end{array}$ & - & $\begin{array}{l}9.60 \text { (exchangeable), } \\
11.29 \text { (exchangeable) }\end{array}$ & & 1.68 & $\mathrm{~s}, 6 \mathrm{H}, 2 \mathrm{x}-\mathrm{COCH} 3)$, both ac & tates \\
\hline
\end{tabular}

Assignments are based on ${ }^{1} \mathrm{H},{ }^{13} \mathrm{C}$, DEPT 135 \& DEPT 90 experiments. $\mathrm{QC}=$ quaternary carbon, $\mathrm{OH}=$ hydroxyl group, OC-CH3- 
Table 2. Various parameters related to antioxidant profile of endophytic extract, compound 1 and 2.

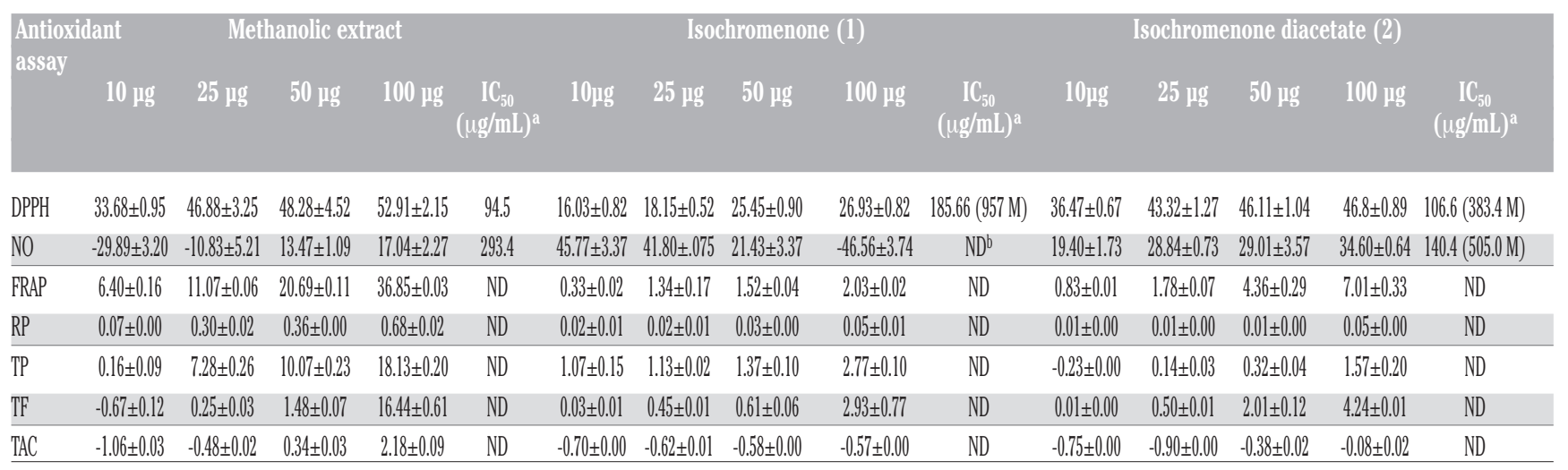

$\mathrm{IC}_{50}$ was calculated from extrapolated values (hypothetical); for ascorbic acid (standard) DPPH=11.5 $\mu \mathrm{g} / \mathrm{mL}$ and NO $=7.25 \mathrm{~g} / \mathrm{mL}$. ND means not determined.

$(0.68 \pm 0.02$ at $100 \mu \mathrm{g} / \mathrm{mL})$ as well as high FSE value $(36.85 \pm 0.03$ at $100 \mu \mathrm{g} / \mathrm{mL})$ in a dosedependent manner, which may be correlated with the presence of high phenolic and flavonoids contents $(18.13 \pm 0.20 \mathrm{GAE}$ and $16.44 \pm 0.61 \mathrm{QE}$ at $100 \mu \mathrm{g} / \mathrm{mL}$ ) in the extract. Compound 1 exhibiting 26.93 $\pm 0.82 \%$ DPPH radical inhibition at $100 \mu \mathrm{g} / \mathrm{mL}$ and nitric oxide radical inhibition was found to be $45.77 \pm 3.37 \%$ at $10 \mu \mathrm{g} / \mathrm{mL}$ (Table 2). Interestingly, DPPH inhibition was decreased as compared to extract whereas NO inhibition increases significantly. The molecule also exhibited positive results for reducing iron radicals (FRAP and RP) but its antioxidant activity was not better than the crude extract. Total antioxidant capacity was not observed in pure molecule striking the fact of the structural difference from ascorbic acid.

Based on these observations, diacetates derivative 2 was also prepared and tested for antioxidant activity. The molecule revealed improved activity for both DPPH and NO inhibition, equivalent to extract i.e. $46.8 \pm 0.89$ and $34.6 \pm 0.64 \%$ at $100 \mu \mathrm{g} / \mathrm{mL}$. Iron reducing activity also improved as compared to pure isolated compound (Table 2).

Antitubercular activity from this fungus has not been reported previously. The antitubercular activity of methanolic extract (MIC) was at $500 \mu \mathrm{g} / \mathrm{mL}$ against Mycobacterium tuberculosis H37RV strain through BACTEC assay. ${ }^{9}$ The minimum inhibitory concentration (MIC) of test compound was noted on the basis of GI (growth index) value. The MIC of standard drugs isoniazid and rifampicin were $0.85 \mathrm{M}$ and $0.28 \mathrm{M}$ respectively.

\section{Conclusions}

In conclusion, the present study has described isolation of 6-hydroxy mullein (1) from A. fumigatus hosted in B. monnieri plant.
To the best of our knowledge this is the first report of this metabolite from this fungus. Our study suggests that not only plants but some other fungi may also be a good source of antioxidant compounds and $A$. fumigatus is one such potential candidate presenting a better scope for production bioactive compounds.

\section{References}

1. Suryanarayanan TS. Endophyte research: going beyond isolation and metabolite documentation. Fungal Ecol 2013;6:561-8.

2. Zhang HW, Song YC, Tan RX. Biology and chemistry of endophytes. Nat Prod Rep 2006;23:753-1.

3. Cragg GM, Newman DJ. Natural products: a continuing source of novel drug leads. Biochim Biophys Acta 2013;1830:3670-95.

4. Kongkeaw C, Dilokthomsakul P, Thanarangsarit $\mathrm{P}$, et al. Meta analysis of randomised controlled trials on cognitive effects of Bacopa monnieri extract. J Ethnopharmacol 2014;151:528-35.

5. Bills GF, Polishook JD. Recovery of endophytic fungi from Chamaecyparis thyoides. Sydowia 1992;44:1-12.

6. Dellaporta SL, Wood J, Hicks JB. A plant DNA Minipreparation version 2. Plant Mol Biol Rep 1983;1:19-22.

7. Sheldrick GM. SHELXS-97, A program for automatic solution of crystal structures; University of Göttingen: Göttingen, Germany, 1997.

8. Sheldrick GM. SHELXL-97, A program for crystal structure refinement, University of Göttingen: Göttingen, Germany, 1997.

9. Siddiqi SH. BACTEC 460 TB SYSTEM, Product and Procedure Manual, MA-0029 (Revision E, May 1996), Becton Dickinson and Company, USA.

10. Singleton VL, Rossi JA. Colorimetry of total phenolics with phosphomolybdic- phos- photungstic acid reagents. Am J Ecol Viticult 1965;16:144-58.

11. Luqman S, Srivastava S, Kumar R, et al. Experimental assessment of Moringa oleifera leaf and fruit for its antistress, antioxidant, and scavenging potential using in vitro and in vivo assays. Evid Based Complement Alternat Med Article 2012;2012:519084.

12. Meda A, Lamien CE, Romito M, et al. Determination of the total phenolic, flavonoid and proline contents in burkina fasan honey, as well as their radical scavenging activity. Food Chem 2005;91:571-7.

13. Yen GC, Chen HY. Antioxidant activity of various teas extracts in relation to their antimutagenicity. J Agr Food Chem 1995;43:27-32.

14. Luqman S, Kumar R, Kaushik S, et al. Antioxidant potential of the root of Vetiveria zizanioides (L.) Nash. Ind J Biochem Biophys 2009;46:122-5.

15. Benzie IFF, Strain JJ. The ferric reducing ability of plasma (FRAP) as a measure of antioxidant power: the FRAP assay. Anal Biochem 1996;239:70-6.

16. Chung YC, Chang CT, Chao WW, et al. Antioxidative activity and safety of the $50 \%$ ethanolic extract from red bean fermented by Bacillus subtilis IMR-NK1. J Agr Food Chem 2002;50:2454-8.

17. Prieto $\mathrm{P}$, Pineda $\mathrm{M}$ Aguilar $\mathrm{M}$. Spectrophotometric quantitation of antioxidant capacity through the formation of a Phosphomolybdenum complex: specific application to the determination of vitamin E. Anal Biochem 1999;269:33741.

18. Negi AS, Luqman S, Srivastava $S$, et al. Antiproliferative and antioxidant activities of Juglans regia fruit extracts. Pharm Biol 2011;49:669-73.

19. Marcocci L, Maguire JJ, Droy-Lafaix MT. Packer L. The nitric oxide scavenging property of Ginkgo biloba extracts EGb 
761. Biochem Biophys Res Commun 1994;201:748-55.

20. Hallmann j, Berg G, Schulz BC. Isolation procedures for endophytic microorganisms. In: Schulz BJE, Boyle CJC, Sieber TN, Eds. Microbial root endophytes (Soli biology). Heidelberg: Springer; 2006. pp 300-319.

21. White TJ, Bruns T, Lee S, Taylor J. Amplification and direct sequencing of fungal ribosomal RNA genes for phylogenetics. In: Innis MA, Gelfand DH, Sninsky
JJ, White TJ. PCR protocols: a guide to methods and applications. San Diego: Academic Press; 1990. pp. 315-322.

22. Shimada A, Kusano M, Takeuchi S, et al. Aspterric acid and 6-hydroxymellein, inhibitors of pollen development in Arabidopsis thaliana, produced by Aspergillus terreus. Z. Naturforsch 2002;57:459-64.

23. Haroon MH, Premaratne SR, Choudhry MI, Dharmaratn HRW. A new -glucuronidase inhibiting butyrolactone from the marine endophytic fungus Aspergillus terreus. Nat Prod Res 2014;27:1060-6.

24. Phattanawasin P, Pojchanakom K, Sotanaphun U. Weed growth inhibitors from Aspergillus fischeri Tistr 3272. Nat Prod Res 2007;21:1286-91.

25. Gamal A, Florence M, Yannick Y, Ahmed L. Characterisation and regulation of new secondary metabolites from Aspergillus ochraceus M18 obtained by UV mutagenesis. Can J Microbiol 2005;51:59-67. 